\title{
Mobile Phones and the Development of Social Capital among Small Malaysian Retailers
}

\author{
Tom E. Julsrud
}

\begin{abstract}
In much literature on social capital, it has been a widely held assertion that networks of informal relations are beneficial for the development of local regions as well as larger nations. In the last decade mobile communication tools have rapidly saturated several markets in Asia, promising to contribute positively to social capital development. This might have important implications for small businesses that in many cases have limited access to PCs. Yet, very few studies have managed to conduct empirical studies of how mobile phones actually are used among small enterprises, and how this affects on the way they handle their business relations. This paper discusses about an in-depth study of small Malaysian retailer's use of mobile phones to build up and sustain their business related connections. Based on qualitative interviews and tracking of their mobile calls /messages we found that the mobile phone was mainly used to support stronger ties in their networks. The boundaries between family, friends and business relations are highly blurred and friends and families are the main communication partner for the mobile use. The mobile phone is also extensively used to coordinate business internal tasks during the day and in-between face-to-face meetings with suppliers.
\end{abstract}

Index Terms - Retailers, Malaysia, SMEs, Mobile communication, Social networks.

\section{INTRODUCTION}

$\mathrm{S}$ mall retailers are a familiar sight wherever you go in Asia. Small shops selling food, beverages, T-shirts, souvenirs and much more are so numerous in most cities that it is practically impossible to avoid running into them. Despite their omnipresence the smaller retail enterprises often get little attention in public debate and their economic impact is often neglected in literature about SMEs (Small and Medium Enterprises). Yet the retail enterprises are overwhelming in their volume, in Malaysia as in most Asian countries. In Malaysia the thousands of small retailers are not only central to provide the population with workplaces; but they play a crucial part in meeting the bulk of Malaysians' needs for food, clothing, everyday services, and much more.

Manuscript received November 11, 2010. Recommended by Prof. Maria Lee on May 20, 2011.

Tom E. Julsrud was with Telenor Research and Innovation Center, Asia Pacific (TRICAP, Selangor Malaysia. He is now with Norwegian Centre for Transport Research, NO-0349 Oslo, Norway (e-mail: tej@ toi.no)
Even though small retailers' investments in technical equipment are often minimal, they have,as most small enterprise owners in Asia, proved to be early adopters of mobile phones [1-4]. Today, it is close to impossible to find a Malaysian retailer without a mobile phone or two within reach. Mobile phones or "hand phones" as they are usually called in this part of the world, have become part of retailer's standard equipment alongside paper, pencils, fax machines and cash registers.

In most papers dealing with communication technologies and enterprises, the use of mobile phone is seen as a part of the general uptake and use of information and communication technologies (ICT). As such it is has been warmly greeted by politicians as well as researchers as a way to make the small enterprises more efficient and competitive [5]. During the last decade, the advent of mobiles has triggered hope that this can be used to strengthen the small enterprises' role in the economy. Alongside other initiatives, increased uptake and use of communication technology is believed to be one central way to help Malaysian SMEs to become more efficient, innovative and competitive [6]. In a report from UNDP, it is hoped that ICT will help to connect Asian SMEs into more efficient industrial clusters:

"The vast potential of ICT to assist SMEs lies in their capacity to instantaneously connect vast networks of SME's across geographical distances at very little cost “(UNDP 2003, p 33).

However, mobile phones may not necessarily work in the same way as computers, and in fact a large group of SMEs in Asia does not even have access to a PC at their workplace. Retailers are in general much more dependent on mobiles than they are on computers. If we are to understand the role of mobile phones for retailers in Malaysia and elsewhere, a more nuanced approach to the analysis of mobile phones is necessary. This paper addresses this issue and sets forth to investigate the way mobiles are used in this group of users, that are among the most numerous type of SMEs in Asia, and more precisely the way it is used to support the social relations and networks that connect their enterprise to the wider networks of partners and collaborators. This paper then links up to the discussion of how mobiles can support and strengthen the social capital of small retailers and in society as such [7-10]. Based on a 
small set of cases, this study provides insight into the kind of communication that is supported through the use of mobiles, including SMS as well as voice communication.

The structure of the paper is as follows: In Section II,we will outline the role of small retailers in Malaysia and explain why it is interesting to study social networks related to these companies. Section III outlines the research approach we use in this study and we will rely on a very general framework, proposing that social relations represent social resources for individuals and enterprises in the form of social capital, that can be developed, sustained and mobilized by the use of mobile phones and other available ICT. Section IV presents the methodology used, and in section V, case studies of small retailers situated in the Selangor district of Malaysia are presented. This chapter has a descriptive style, drawing on qualitative as well as quantitative data. In the sixth part we will discuss the findings in more detail, highlight some of the core insights, and discuss the role mobile phones seems to play in supporting the retailers' relations and (therefore also) their social capital.

\section{SMALl Retail ENTERPRISES In MALAYSiA}

Small enterprises are not a very homogenous group in Malaysia or elsewhere. Often lumped together within the overall small and Medium sized Enterprise' category (SME), this classification tends to mix companies of very different types and qualities. ${ }^{1}$ In general however, small enterprises are expected to have fewer than twenty employees. Micro enterprises in Malaysian statistical sources are usually considered as a subgroup including enterprises with five or less employees.

Even though the definitions of small enterprises often vary across national statistics, there is no doubt that this group represents a large bulk of enterprises in most Asian economies. Overall about $99.2 \%$ of all Malaysian SMEs are categorized as SMEs [12]. Small enterprises are usually found within the three broad sectors: agriculture, manufacturing and services. Retailers represent the largest groups within the latter category and there are at least 150,000 retailers in Malaysia today [3]. In addition, there exist a significant number of informal retailers, operating outside the official statistics. The exact number for this for Malaysia is difficult to estimate, but looking at similar numbers in other Asian countries, it is likely to be significant [13]. Even if this sector involves a lot of

\footnotetext{
${ }^{1}$ Different definitions are used to classify small and medium sized enterprises (SME). In Malaysian statistics SME is used to describe enterprises that have less than 50 employees and a turnover less than 5 million RM. Medium sized enterprises have from 20-50 employees, small enterprises from 5-19 employees and micro enterprises less than 5. Criteria for turnover are sometimes also used in addition or as a supplement to numbers of employees. (see also Saleh and Ndubusi . European statistics tends to include larger enterprises in definitions of micro-enterprises, often less than 10 employees [11]
}

companies and employees, the retail sector consists of many small units: over $85 \%$ of all retailers have less than five employees and over $99.2 \%$ have less than 20 employees.

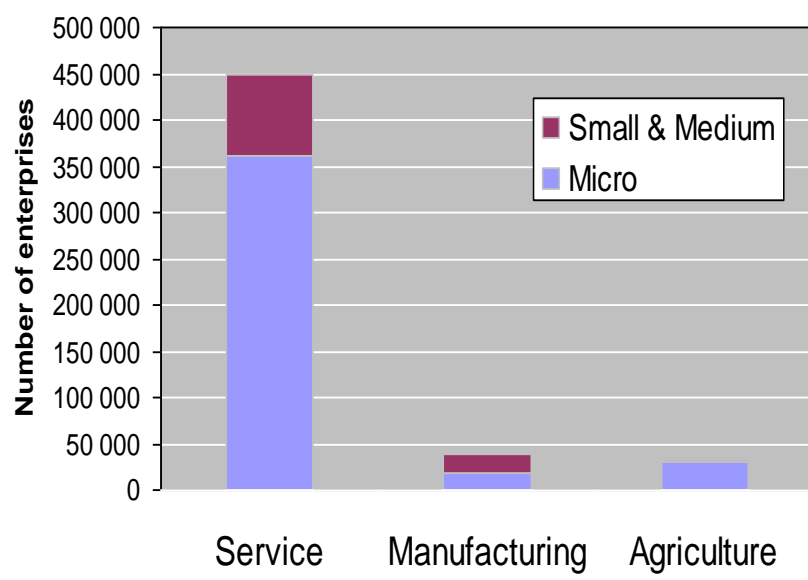

Fig.1. Overview of number of small enterprises and category, Malaysia 2005 (Source: SMIDEC)

The large number of small players makes the retail sector flexible, but also vulnerable. It is flexible because it can adapt quickly to change in accordance with shifts in the economy; small companies are easy to set up but also easy to close down if necessary. In many cases, small retailers have more than one business going on, so phasing out one does not have to be highly dramatic. However, it is also vulnerable because smaller companies might have fewer resources to spend on building up competence and knowledge necessary to increase competitiveness [14, 15]. Their capacity to spend time and resources on for instance implementing new technical solutions is usually very limited. Thus many small retail companies run the risk of being wiped out by larger retail stores offering cheaper products of increased quality $[3,6]$. The fact that retailers in general are organized as multiple small entities makes interaction and collaboration with other parties particularly important. Small retailers usually need to be in contact with at least a handful of suppliers or wholesalers, as well as getting continuous help from friends and family members. As we will come to the later part of this paper, there are often different types of partners or contact persons involved as well.

A particular common constellation in Asia is the family businesses, where the boundaries between family members and employees are highly blurred. In such businesses family ties often connect clusters of small companies that collaborate within certain branches, as when father, sons and in-laws establish similar businesses within the same sector. Such enterprises are famous for putting a high value on a dense network of informal social relations ("guanxi") [1, 16, 17]. Although Malaysia is a multicultural nation, the Chinese part of the population is dominant amongst the small retail shops. This makes the Chinese business culture a part of the cases we discuss in this paper. We will come back to this in the last part of the paper. 


\section{SME IN A NeTWORK PERSPECTIVE}

\section{A. Social Capital Theories}

Social networks have for a long time been recognized as a central theoretical and methodological approach to studies of small enterprises [18-20]. Several recent studies have suggested that the social relations cutting across small enterprises are a vital element for sharing of knowledge and business innovations [21-23]. Such benefits are often described as social capital, i.e. a form of resources embedded in a particular set of social relations and networks operating across the boundaries of the individual enterprise. Different variations of social capital theory exist, emphasizing structural, relational or cultural aspects of these relations [24-26]. A full review of the large theoretical field of social capital falls beyond the ambitions of this paper. For the purpose of this work, it is sufficient to note that according to theories of social capital, social relations represent resources that can later give returns. As a form of capital, the relational (social) capital is however less tangible and less of an individual possession than money, stocks or property. Needless to say, perhaps, this type of capital is also much more difficult to analyze and measure ${ }^{2}$.

Social capital oriented approaches to organizations are frequently linked to other theoretical positions, such as resource dependency theory $[27,28]$. The resource dependency theories are a point of departure for Nan Lin, who explicitly locates social capital in the tradition of neocapital theory as well as in Granovetter's description of network as important embedded resources for economic actors [28-30]. From his point of view, social capital is seen as investment that actors make in social relations with the hope and expectancy of some form of return at a later stage. These are returns that go beyond what is usually accounted for by traditional "capital". In general it facilitates four types of returns: the flow of information, that can be used to exert influence on other agents, it helps build up social credentials and reinforces identity and recognition. For instance by forging a tie with a specific other SME, a retailer may get access to useful information about a supplier or wholesaler at a later stage. Or by forging a tie with a powerful wholesaler it might build up his reputation as a trustworthy partner, increasing his social credentials and reputation. On an analytical level, one may distinguish between both instrumental and expressive returns: the first type includes economic and political returns; the second includes returns in the form of mental and physical health and other forms of life satisfaction (Lin 1998).

Following a resource dependency approach, we may further draw a distinction between network structure, accessibility

\footnotetext{
${ }^{2}$ A term that is related to social capital is network capital. According to Larsen, Urry and Axhausen, this encompasses all artifacts that increase the accessibility of ties in social networks. In this perspective the mobile phone is the network capital, along with trains, cars, roads, etc. See also Rettie on mobile phones as a particular form of network capital.
}

of resources in a network, mobilization of these resources and potential returns. In contrast to some other approaches, this approach perceives an actor's position in a network (or a particular structure), not as social capital per se, but as factors influencing the ability to gain access to resources. The accessibility of resources, then, is analytically separated from general collective assets such as trust and social norms, even though these affect on the ability to access resources in a network (see model below). Finally the accessibility is seen as distinct from the possible mobilization of these resources and the returns that they can give.

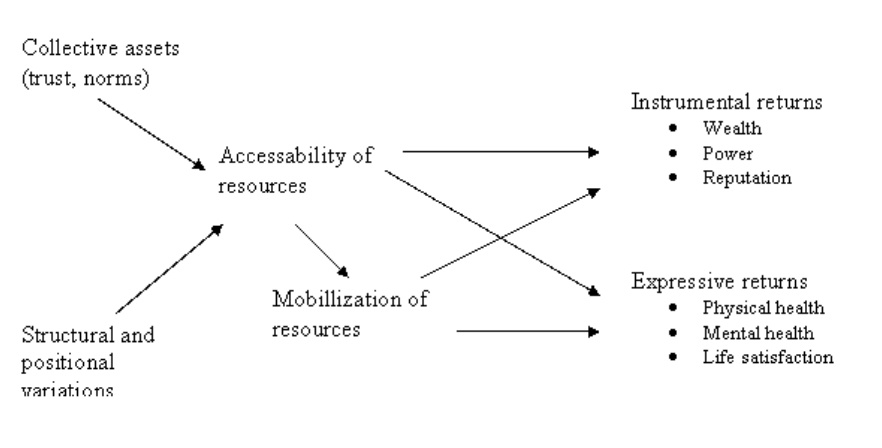

Fig 2. A general social capital framework

Figure 2 shows the rough conceptual model that has been useful to our study, based on the conception of social capital as a resource. Trust is here seen as a quality of a particular dyadic tie or as a generalized norm perceived as one crucial factor that affects on the accessibility of resources in a network. In SME networks where trust is high, more resources can be expected to circulate between partners, and less effort is needed to check or secure against fraud or cheating [31, 32]. We would like to add, however, that (increased) trust also can be seen as an important return, usually strengthening positive feelings and what Giddens calls "ontological security" [33]. ${ }^{3}$

Clearly, it is possible to think about relations as resources not only for individuals, but also for the larger organization and constellations of organizations. Social capital can also represent collective goods. Most theories in this field agree that social capital operates on both micro and macro levels, even though the boundaries between these levels are indeed fuzzy ${ }^{45}$ [25]. It is frequently held that SMEs connected in larger clusters may represent significant benefits for people working in the enterprises, the organizations, as well as for the larger region they belong to $[37,38]$. Still, even if social

\footnotetext{
${ }^{3}$ The role of trust for network developments among enterprises is more closely described elsewhere.

${ }^{4}$ Definitions of social capital often try to capture the multiple levels. Nahapieth and Ghoshal, for instance, state that this is: "the sum of the actual and potential resources embedded within, available through, and derived from the network of relationships possessed by an individual or social unit" [24].

5 In organizations, a distinction is sometimes made between individual and corporate social capital [36]
} 
capital figures on a group or institutional level, it is the employees and managers in the enterprises who make the maintenance and reproduction of social capital possible. It therefore makes sense to analyze social capital as individual relations and networks.

This paper focuses mainly on the types of relations and networks the managers and employees access through their daily usage of mobile communication. We will however direct attention to the mobiles as a tool to develop accessibility and mobilize resources.

\section{B. Type Of Relations}

What kind of relations is important for small enterprises? Following economically oriented studies, on an overall level, a distinction is often drawn between three general types of relations: informal social relations, market relations and hierarchical relations [39]. The difference and current transformation between these networks in modern markets is widely discussed in economic literature. For instance, recent contributors have argued that informal relations are becoming more and more important in modern organizations, at the expense of the other two, propelling a more community oriented type of organization [40]. Most business relations consist of a mix of these dimensions rather than being purely market based, hierarchical or social [41]. In particular, relations in small enterprises tend to blur the distinction between the private/social, market related and hierarchical. As already mentioned, the informal relations tend to play a particularly important role for many small enterprises in Asia [1].

Not only do the different coordination mechanisms of market, hierarchies and informal ties play a role when targeting the small enterprises networks, but also the quality of the ties should be considered important. From a more actor oriented point of view, a branch of studies has focused on the quality and the quantity of the enterprise managers' individual social networks [42]. One central finding from these studies is that because relations are created by processes of ongoing interaction, their structure fluctuates and their boundaries are usually "fuzzy" [43]. And because the managers are embedded in such fluctuating networks, it is unlikely that they will make decisions about their firms in isolation of these influences. Another central finding is that the size and constellation of the individual network effect on the efficiency of the manager and their company. For entrepreneurs, the value of having a rich network of contact persons has been documented as vital, in particular in initial stages of the development [44]. Still, these personal networks are not assembled within a single type of relations, but are found in private realms of life as well as among business colleagues or partners.

The core area of interest for the bulk of social network studies lies within the realm of informal social networks. Such relations are in turn often categorized as stronger or weaker, where the weaker form is typical for occasional interaction between acquaintances while the stronger form is more typical for relatives and close friends ${ }^{6}$. Much research has elaborated on the distinction between strong and weak ties and a general argument coming out of the 'strength of weak tie' hypothesis is that weaker ties have benefits related to giving access to new information that make them particularly important for knowledge development and information access. On the other hand, stronger ties have proven to be more important for the development of trust and stability as well as the transfer of tacit knowledge [4648]. Still, it is difficult to make an absolute distinction between strong and weak qualities of relations. In practice, most work-based relations fall somewhere "in between" the weak and strong ties [49, 50]. In small enterprises, most weak ties will typical go beyond the individual enterprise towards people in other businesses or organizations. Stronger ties are on the other hand, more common for the internal relations of colleagues and managers. As in all organizations, however, the formal ties and the more market oriented relations will interfere with the more informal ties.

In network studies, some bodies of work have been particularly occupied with analyzing the overall structure of ties, related to social capital. From a whole-network point of view, social capital is a product not only of the kind of relation but the constellation of these ties in denser or more open structures $[48,51]$. The value of denser communities is sometimes contrasted with the benefits of more open and wide spanning networks connecting distant clusters. Still, empirical evidence suggests that the value of particular constellations must be seen in relation also to the type of relations involved and the particular type of organizational context involved [46, 52]. Following the framework suggested earlier, however, structure and structural positions are not social capital per se, but important factors impacting on the accessibility of resources.

In summary then, an examination of the small businesses networks important for the development of social capital, should include relations based on informality (like friendship), on hierarchies (like manager-subordinate), on markets (buyer-seller) and any combinations of these. The intensity of these relations will vary over time, as will the particular quality of a relation. For example; a business relation can turn into a friendship and a friendship might develop into a family tie. Following the social capital theoretical framework outlined above, such networks represent resources that can be mobilized for the return of instrumental and expressive returns. Whether the mobile phone actually can play a role in these processes, is the topic for the subsequent parts of this paper.

\footnotetext{
${ }^{6}$ The concept was initially proposed by Mark Granovetter. According to Granovetter strong ties can be described as "ties that have a combination of long duration, high emotional intensity, intimacy and reciprocity " [45].
} 


\section{Social Networks And Mobile Communication}

According to most network approaches regular communication between partners is a criterion for the development of interpersonal social relations. The general point of view shared by most network analysis (and social capital theories) is that communication between humans may over time develop into relations and networks [53-56]. Following this line of thought, modern ICT and mobile telephones, representing 'communication enhancing devices', should have much to offer small enterprises in developing, strengthening or exploiting their social capital. Compared to a landline phone, the mobile not only have the benefit of being portable; it usually also have several additional functions, like address book, texting options, and more (dependent on model and network available). And recently, due to the prepaid subscription offers, it has also been a cheaper option than the landlines.

Some recent studies have provided evidence that there actually is a positive link between social capital and mobile phone usage on a community level. Goodman found in two (non-representative) surveys from South Africa and Tanzania that mobile phone users were more active in participating in local community groups than non-users. The mobile users also had a wider network of both weaker and stronger relations than non-mobile users [7]. Action research with female entrepreneurs in India also seems to support the idea that the mobile can be used to develop social relations and increase social capital [57].

Referring to the general model above, the mobile phone offers opportunities to strengthen enterprises' social capital in at least three different ways: first it can be used to invest in social relations and resources. In this way it is a tool for keeping relations alive and "giving" partners and collaborators attention and support. Mobile phones may make it more easy and convenient to develop and sustain social relations that are at a distance, and SMS and MMS have proven to be important as a tool to sustain both affective and instrumental communication, even at work [58, 59]. Second, it can be used to increase their accessibility to others. Just by having a phone, the employees or managers can more easily be reached by millions of others even when outside offices. Much like email and social network software, a mobile phone opens up a world of latent ties, i.e possible contacts [60]. Third, it can be used to mobilize resources in a pre-existing social network. Given that a manager or employee already have access to a certain number of connections, the mobile phone can make it easier to exploit these resources in a very short time.

In practice, it is difficult to distinguish strongly between these processes. A typical communication situation between partners or friends may include a mix of different purposes. However, insights indicating whom employees and managers in SMEs call or send messages to during the day can give some indications as to what kind of resources they access with their mobile. The study presented here analyses these mobile supported networks by quantitative as well as qualitative means. Since we do not have much information on the content of the communication, it is difficult to analyze what kind of returns that they actually get from the mobile-based contacts. Our focus here is therefore focusing on what kind of relational resources that is addressed are developed by the use of mobile phones dialogues and messages.

\section{METHODOLOGY}

\section{A. Comparative Case Studies}

This study is based on a series of case studies ${ }^{7}$ of small enterprises in Malaysia. Comparative case studies usually deploy a cross-case design, where several similar cases are compared [61, 62]. Typically such studies intend to explain similarities between different cases, or differences between similar cases. In any way the cases are connected, or part of the same group, in one way or another. A distinction is usually made between studies that are case-based or variable-oriented [62]. In this paper a 'mixed strategy' is used, where case-based and variable-based methods are combined [62]. First, we will focus on the cases one by one. Second, we go on to analyze certain variables cutting across all cases related to their social network use. In this second phase, the analysis thus becomes more variable-oriented and focused on developing theory.

\section{B. Case Selection}

The cases in this paper are selected on the basis of their general belonging to the category of 'small Malaysian retailers'. Moreover, they are all located in the Kuala Lumpur district, meaning that at least the general national and regional cultural context can be expected to be fairly similar across the cases. The cases differ, however, along the dimension of size and branches: two of the cases are smaller (below five employees), one is slightly bigger. They are also picked from two different sub-segments: food and beverage, and motor equipment and vehicles. This "slight diversity" was allowed to capture some of the diversity in practices within the segment "retailers".

\section{Techniques And Tools Used}

The study is based on a mix of qualitative and quantitative techniques. For the qualitative part we conducted interviews with managers and with two to three employees in all

\footnotetext{
${ }^{7}$ In general, case studies can be described as a research strategy aimed at studying a limited number of phenomena within their natural context. Yin describes this as: "an investigation of a contemporary phenomenon within its real life context, especially when the boundaries between phenomenon and context are not clearly evident." [61].

${ }^{8}$ Note that the three cases presented in this paper are part of a study of a larger number of SME cases from different business segments.
} 
enterprises. For each enterprise three employees were selected randomly (to avoid a 'managerial bias'). The interview lasted for about 30-50 minutes and was recorded and later coded and analyzed with the use of Alas-Ti software. In addition, we asked the manager to draw his network of relations of relevance for his daily work.

The quantitative part involved a short survey distributed to all employees in the companies. The questionnaire included a general information section asking about informants' age, type of work, media usage, subscription type, and work mobility. The second section was used to track the individuals' networks based on their most recent use of mobile phones. A traditional 'ego-network design' was included to capture ingoing and outgoing phone calls, text messages (SMS) and e-mails [63, 64]. Rather than using a traditional name generator, however, we based the personal network on the actual incoming and outgoing mobile traffic. To do this, we first asked the informants to open the call directory in their mobile phone. Then we asked them to read off and register the last ten ingoing and outgoing calls and messages, and classify them in accordance with seven predefined categories. The same procedure was then followed for SMS.

Mapping media use as relational networks has the advantage that it gives a more detailed picture than traditional "average scores", and it gives the researcher a better picture of how different media is used to connect to different nodes in a network. Obviously, tracking media use based on record $\log$ s is a more reliable way of getting data than information from informants' memory [65]. There is always a risk that individuals do not register what they see in the log or that they change this to make them more 'central' in the enterprise. We have no reason to believe, however, that this happened in our study. Analyzing social networks based on mediated interaction runs the risk of being narrowly concerned about only a few media channels, forgetting about communication taking part in different media and channels [66]. We should not therefore expect the networks expressed through media-based to reflect a "correct" picture of social relations or communication going on in the enterprise. What it does give is an indication of what kind of relations that mobile phones and SMS were used to support. Here, we will compare the traffic diagrams with the information from the qualitative inquiry.

\section{CASE Studies}

\section{A. Lhl Wholesale}

General: This enterprise trades dry foods from a central location in Ampang, outside the capitol of Kuala Lumpur (KL). The central food storage is an outlet selling to smaller retailers and individual customers. Related to the enterprise is also a small network of shops located in the region. At the central premises orders from the smaller outlets are handled, as well as orders from drive-in customers. The enterprise comprises about 20 employees, of whom a significant part is foreign workers. For LHL there were basically two different kinds of customers coming to the store: small visitors buying goods or small retailers buying larger amounts of goods. Both, however, required person-to-person interaction with the staff.

Work task: All retailers were involved in some manual work tasks in the shop or warehouse, including sending or packing the goods to customers. As for LHL, it involved filling up lorries and cars with the assigned products and filling up the stock with new goods as they arrived. The manager was very central in all work, even though he delegated some responsibility to the warehouse manager and the administrative officer. This officer was in charge of contact with a lot of foreign workers and the two drivers. The manager was the only one that communicated with the suppliers. Much of the day-to-day work in the store was coordinated by informal communication among the workers. Typically, they would turn to each other for immediate information about where certain items were located. A large group of foreign workers operated in the warehouse and the informal communication seemed to be more active among these workers.

Key Relations: LHL was, according to the manager, a "typical Chinese family business". Connected to the enterprise were five other outlets run by relatives of the LHL manager. This core network of family members was essential as much of the internal communication in the enterprise was structures between these brothers. In addition, a network of suppliers was important for LHL. This included 2-300 different producers of drinks, sweets, cigarettes etc. The manager of LHL also had strong ties to other small enterprises in the local area and elsewhere, and sometimes he would mobilize these contacts to buy larger stocks of goods at lower prices. To the core network we should add a stable network of customers, mainly small retailers in the KL district.

Media access: In LHL the mobile was used on a daily basis by all employees (See fig. 3). The manager used the mobile phone book as a "memory" when being contacted by customers. It is worth noting, however, that even though the mobile was the most used medium, there were PCs available in all enterprises, and at least by some it was used on a daily basis. The use of computers was, however, very basic, usually limited to surfing the net and exchanging emails. Telefax was used daily to communicate with suppliers and other outlets.

Use of mobile across networks: Looking at the phone calls conducted in the company for the last ten days, it turned out that SMS and mobile calls followed very similar patterns. Most calls were to family and friends and to colleagues at work (see fig 4). The mobile was a central tool for coordinating work tasks to the other outlets, to the drivers and to coordinate work at the shop floor. Probably, a lot of 
the calls to family members were due to the fact that partners in the firm were all family members. This is the case for the brothers operating outlets in other parts of the KL area. More importantly, however, many employees in this company were foreign workers. An important reason for them to buy phones, was to keep in contact with family members in their home country. As such, this makes the family/friends category very large. The similarity in the use of SMS is striking, and an analysis of incoming and outgoing calls/messages also indicates a strong reciprocity in the in- and outgoing calls/ messages.

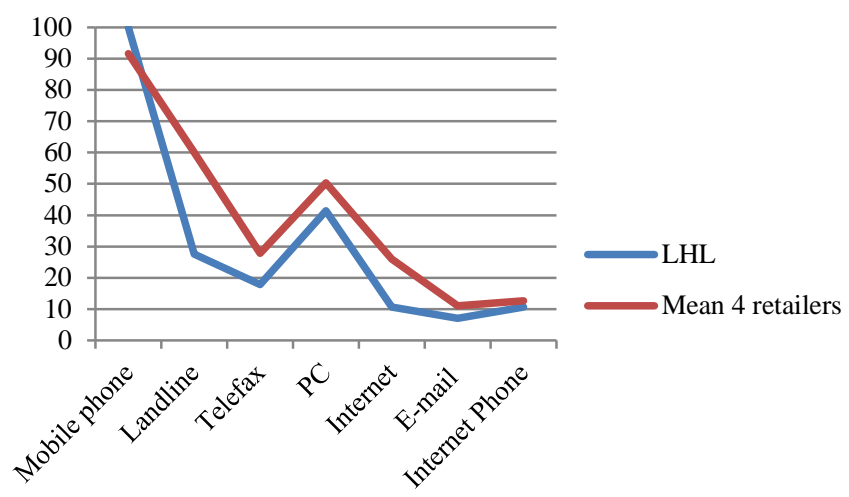

Fig 3. Daily media use among managers and employees in LHL Percent.

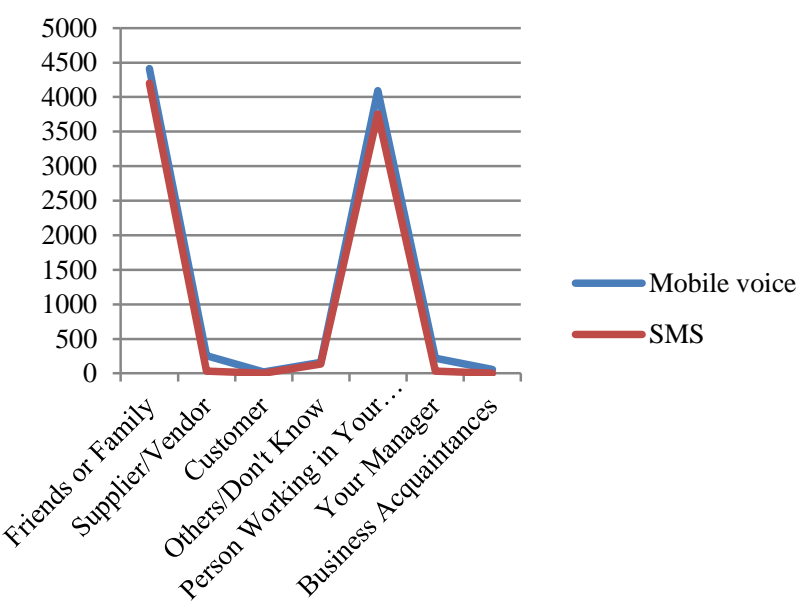

Fig. 4. Numbers of in- and outgoing calls and SMSs among managers and employees in LHL. Last 10 days.

\section{B. Kang Zheng}

General: Kang Zheng is a small outlet in the Subang area of KL that trades herbs and traditional grocery goods. The main business is the selling of the herb medicine, while the grocery is a side business that gives them additional income. The shop is run as a small family business, including a man and wife as well as a young Cambodian assistant.

Work tasks: Most work is conducted at the small shop, where customers come and buy herbs recommended or prescribed by Chinese doctors. In addition, there is administrative work related to ordering, billing etc. The family sometimes gets help and assistance from relatives running a grocery shop in a town nearby.
Key relations: The closest partner was the relatives nearby who did similar business. But also neighbors were counted in as important relations. The manager had established a close collaboration with doctors prescribing herbs as a part of the recommended treatment for patients. This had turned out to be a central part of the business for the small company. In addition the enterprise had a set of suppliers feeding the regular shop with food and beverages.

Media access: At Kang Zheng the mobile was used in combination with landline available in the shop (See fig. 5). Most calls were made from the mobile, and both partners had individual mobile lines. The couple had a special arrangement: the man had a mobile phone that was used for work purposes, while his wife's mobile phone was used for private calls. A PC in the backroom was used by the husband/manager, mainly to surf the web looking for prices and products.

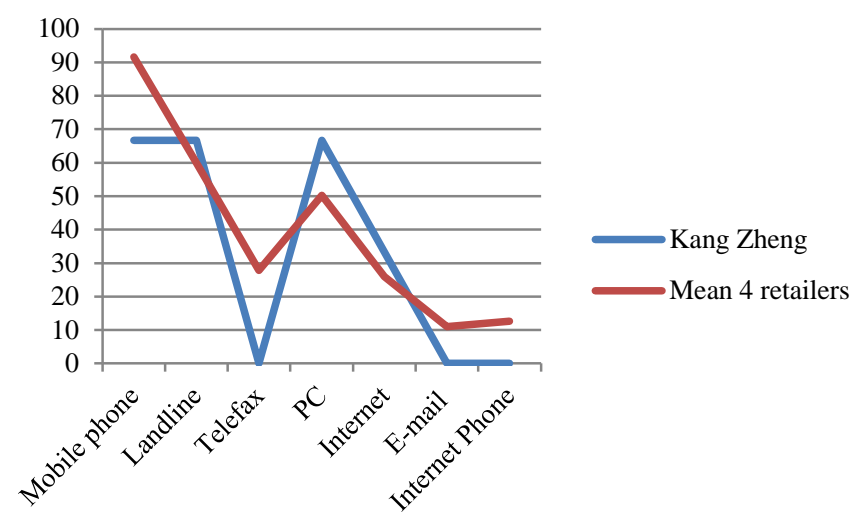

Fig. 5. Daily media use among managers and employees in KZ. Percent

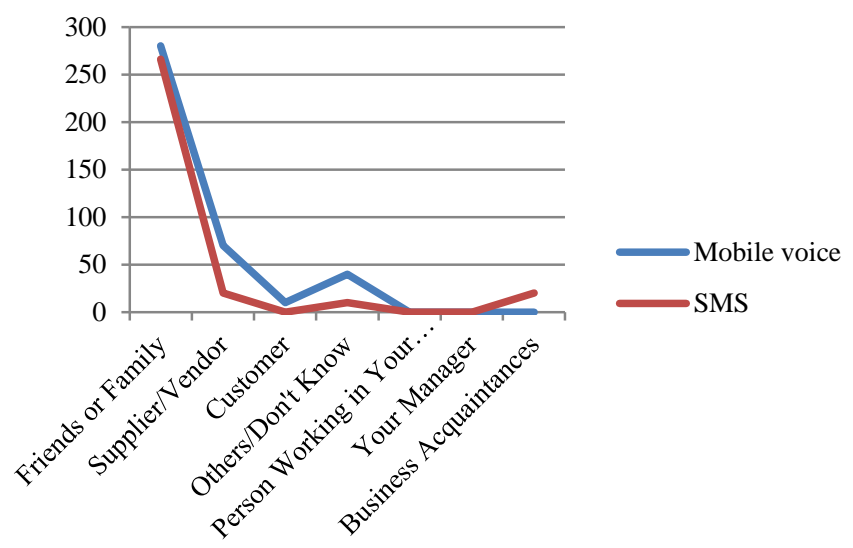

Fig. 6. Numbers of in -and outgoing calls and SMSs among managers and employees in KZ. Last 10 days.

Media use across the networks: As with the previous enterprise, most calls were also here to/from friends and family members (See fig. 6). SMS use is in general sent to the same persons as are being called. The suppliers, however, are supported more frequently by the use of mobile phone calls than by the use of SMS. Compared to LHL, the company internal calls are lacking but this is obviously due to the small size of the enterprise. 


\section{Meng Chong Motor}

This enterprise has been in the motorcycle repair business for 18 years. It span off from the husband of the owner's involvement in licensing motors and road tax payments. The business involves insurance, spare parts repairs, and buying and selling of motorbikes. As a side business, this small retailer also handles insurance of motor vehicles (mostly from walk-in clients) and helps some foreigners apply for an international license by sending remittances to Indonesia. To help in the business, one senior mechanic and one temporary employed mechanic from Myanmar are employed.

Work tasks: The main work processes are motor repair, ordering spare parts, handling motor insurances, renewing road tax, and collecting money. There is no record system for an inventory of spare parts. What is usually done is to separate parts by brand, find the parts when needed, and order when there is no more stock.

Key relations: This SME's network consists of three suppliers of spare parts, two insurance companies, an agent in Indonesia for the remittance side business, and other shops within the area which do not have insurance products and buys from them. Among the motor repair clients within the community, they have over 100 insurance customers every month. The network of customers was very local, where as a lot of the customers were returning ones.

Media access: The mobile was used on a daily basis as suppliers of spare parts call every day to check any orders. As for the other cases, the mobile was the dominant media that everyone had access to (see fig. 7). The senior mechanic received phone calls from suppliers to ask about stocks (ask about price, availability of stocks). A voice call was preferred because it is faster. The senior mechanic also received calls from clients regarding motor repairs. The other mechanic used his own mobile but mainly for personal use (e.g., calling his family in Myanmar).

The landline was used as a back-up device when the employee could not connect through the mobile or the reception is not clear. Sometimes, calls were made ten times to coordinate and to check prices and stocks with suppliers. The fax machine was used more for insurance, road tax, invoice and to communicate with agents in Indonesia on the remittance side business. The need for written evidence and copies for records were central motives of sticking to the fax. Two computers were used regularly by the owner: one each for different insurance companies they made use of. The Internet is used simultaneously for insurance companies, although not on a daily basis.

Media use across the networks: Interestingly, this enterprise displays a somewhat different picture than the other two enterprises (See fig. 8). The family/friends ties are still dominating the volume of calls and messages. Mobiles are also used a lot to communicate with business acquaintances. This is certainly to a large degree to call contacts in the insurance companies. Still, SMS does not follow the pattern of the calls but is used primarily as a tool to support customers. These are customers for the auto shop as well as for the related insurance business. The divergent pattern of texting was partly due to a need for informing customer about when to pick up their repaired motorcycles; partly to coordinate the money transferring for foreign workers in the local area.

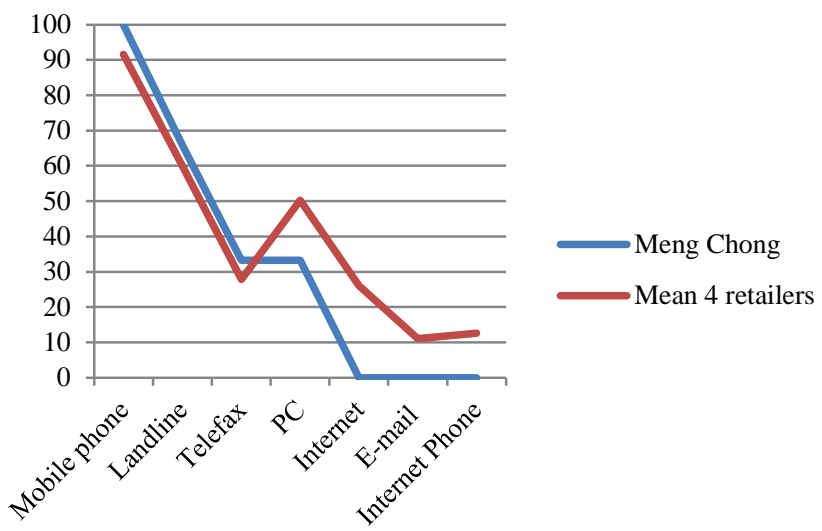

Fig.7. Daily media use among managers and employees in Meng Chong Motor. Percent.

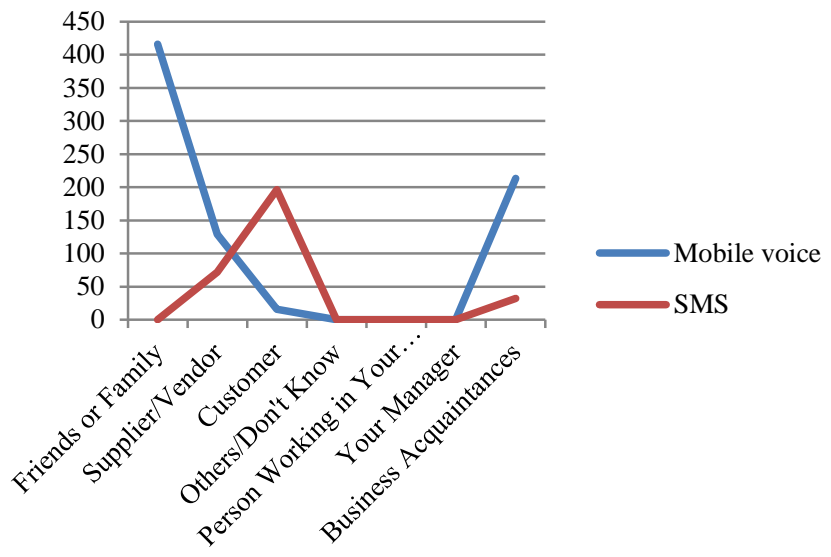

Fig. 8. Numbers of in -and outgoing calls and SMSs among managers and employees in Meng Chong. Last 10 days.

\section{DISCUSSION}

This paper proposes a social capital framework to better understand the value of mobile phones for small retailers in Malaysia. Given the premise of these theories, that social relations represent resources for enterprises, the way in which the mobile is used to strengthen or support these relations is of interest. In this section we will point at some of the core findings from studying mobile use among the three retailers and then discuss some implications for the future role of mobiles to develop social capital among Malaysian retailers.

\section{A. Core Insights}

Mobile as a tool to support stronger ties: The mobile phone was in all our retail cases the most central tool for communication during the work day. Even though all 
actually had access to a PC with Internet at home or in the back room, this was mainly a tool they used for searching on the web and Internet banking. However, we found that the mobile was mainly used to support family relations and relations to friends. This is interesting given that we asked for calls made on the phone used for work. Accordingly, the mobile seemed primarily, to be a tool to support the stronger personal ties also during work hours. This finding is in line with results emerging from similar studies conducted amongst SMEs in Africa. A survey of micro entrepreneurs in Rwanda, using mobile phone call logs, found that as much as two thirds of all calls were to family and friends. In a follow-up survey, it was found that calls to friends involved as much as $45 \%$ of all calls, and family members $26 \%[67,68]$.

In our cases the findings can be explained by at least three central factors: firstly by the fact that the small retailers operated in very close circles, relying heavily on family and friends. The networks of business partners were in most cases long-time relations that were based on trust rather than on formal contracts. In some cases the colleagues at the work actually was also part of their families (spouses , brothers, in-laws). This is in line with what has been written earlier on Chinese family businesses as having: "strong family ties, sharing and pooling of resources, efficient use of manpower practice of thrift, use of low gearing and flexibility of operations" [1]. From our cases it appears that the retailers in Malaysia are developing their SMEs much in accordance with these traditions. In particular for the smallest enterprises (like Kang Zheng) family and work are very hard to separate, and sisters, brothers and parents were as much colleagues as family members. Secondly, in all our cases a significant number of employees were immigrants from neighboring countries. These workers use the mobile extensively to keep in contact with their families at home. Some employees said that their main motivations for purchase of mobiles were to make long distant phone calls to their home countries. This clearly contributed to the large number of family and friends calls. A third reason was that many employees in these small retail enterprises pay for their own mobile phone use and use the same phone for private as for business. The employer sometimes would compensate for the employer if he or she used the phone extensively for work. The result was, however, that the mobile phone had become a hub for all kinds of social relations, not only work relations.

The fact that the bulk of mobile communication was to support ties with family and friends should not however be seen as an indicator of mobiles becoming a medium for nonwork relations. On the contrary, mobiles are also used heavily to support communication with colleagues and partners during work time. For the somewhat larger SMEs (like LHL) the internal communication was actually as high as the number of calls/SMS to family and friends. Thus the internal day-to-day coordination was also an important use of the mobile. Among the retailers both mobile voice and SMS were used for private as well as business needs. In general, the large bulk of family calls and messages in these small firms, seem to strengthen the argument that there is a strong overlap between different type of relation (market, trust, hierarchies) among small firms [39, 40].

Mobile as tool to support internal work coordination: In the larger retailer and wholesaler companies the mobile was widely used as a tool to coordinate work during the day. The mobile was used to inform each other continuously about detailed work instructions, check out prices and give instructions to the two drivers. SMS was here seen as particularly convenient for communicating detailed information that needed to be "documented" or remembered. As such, it had become something of a channel for coordinating internal tasks, perhaps similar to how email functions in larger and more bureaucratic organizations [69].

SMS as an emerging customer-relation tool: In most cases mobile voice and SMS followed similar relational patterns: i.e. SMS and mobile voice were used in concert to support the same relations to family and friends, as well as to coordinate work. This is illustrated well in the LHL and the Kang Zheng cases. However, in the Meng Chong case we found a strikingly divergent pattern of use for SMS and mobile talk across the enterprise: SMS had developed into a customer-relation tool ${ }^{9}$. Here SMS was used to inform customers about their repaired cars and other customers about the insurance business. The side business, to support Indonesians to transfer money also generated a lot of SMS interaction:

"At 4.15 pm I will receive a SMS to notify me that the money has been already credited to the particular account at Indonesia and I will SMS to inform the Indonesian here who sends the money." (Meng Chong manager)

Thus, SMS had here developed into a central tool for handling the business interaction. We should note firstly, that this is possible, since the penetration among Malaysians now is so high that all their customers could be expected to have access to a mobile phone. Secondly, we should also note that this is probably particularly relevant for more service oriented retailers and retailers with regular customers.

Mobile as coordinator in-between face-to-face meetings: As mentioned, the SMEs relied heavily on a durable and local network of relations to wholesalers, suppliers and even customers. The suppliers of goods to the enterprises and their important partners were all based on face-to-face contact. The mobile was used to support these relations, although not as a replacement for face-to-face meetings, but

\footnotetext{
${ }^{9}$ In the study there was a very high reciprocity between ingoing and outgoing calls.
} 
to coordinate between these meeting such as taking care of the more instrumental communication in-between the meetings. Take for instance Kangh Zeng, the small herb dealer. The manager described that he mostly uses the mobile to coordinate prices and deliverables, and to clear out problems:

"Most of the time, it is ordering, sometimes when the prices are not stated in the invoice we also call them or when there is a problem with the goods we have sent."

Still the relations to the partners are mainly based on regular meetings in the shop. On the relations to the Chinese doctors the manager emphasizes this:

"Basically they are my friends; they will come here 1 to 2 times a month to share their experience in terms of the pricing, the medicine, the quality of the medicine, how to mix the medicine and herb because different herbs have different use". (Kang Zengh manager)

The supplier of other goods to the shop also comes to visit the shop regularly; the mobile is used to regulate or prepare in-between these meetings:

"They will come service us in two weeks, one week, or every day. Every week they will come to serve. If we lack something, then we will call them" (Kang Zheng, wife)

This herb dealer is clearly strongly attached to their business partners and suppliers, as was the case for the other retailers. For these relations there seems to be a strong need for physical meetings. The coordination in-between is however mainly dealt with by the use of mobile calls and messages. Thus, the use of mobile phone is closely related to physical meetings and business travelling. Rather than being a substitute for travelling, however, the mobile phone was used to coordinate and keep the "positive spirit" alive in between the regular meetings. This finding resembles similarities to what has been reported in studies of the way young professionals and young adults use the mobile phone to coordinate in between physical meetings [70-72].

Mobile as a relational data bank: Finally we found that in all retailers the mobile was used to keep track of relations to multiple customers. An important difference between a fixed line phone and a mobile is the possibility to save multiple numbers in the SIM card or the phone memory. For the managers in our retail business this is a crucial function. The manager in LHL, for instance, told us that he had all his core customers in his mobile phone:

"I rely on my mobile phone, because all the index is inside and I don't need to dial all the number, that's why I cannot lose my phone, if I lose the phone then my memory is all gone..." (Manager LHL)

The manager in Meng Chong had two phones. This helped him to sustain a certain control of family and private oriented relations. The young couple running Kang Zheng, however, had another arrangement; the wife used her phone mainly for private calls and the husband took care of the professional connections. By sharing the responsibilities and using two phones the couple had a shared responsibility to handle different parts of their networks.

\section{B. The Impact Of Mobiles On Retailers 'Relations And Networks}

Looking back at the resource based model of social capital presented earlier, a distinction was made between accessibility and mobilization of relational resources. From our data is seems clear that the use of mobiles affected directly the retailers' accessibility to social relations and their resources in different ways. On the one hand, the portability of mobile phones made managers and employees more accessible for the customer, as well as for each other and their network of collaborating partners during the work day. The managers and employees in our cases had to a large extent abandoned the fixed line phone to increase their own accessibility by using a mobile phone (the fixed line phone was still used, but mostly for incoming calls from customers). The fast access to contacts through the mobile phone book was one interesting element here that seemed to have increased the accessibility of network resources. It made the customer register portable and easy to update. Another was the use of SMS to access customers (in particular in the last case). The messaging channel appeared as a new and more efficient way to relate to customers within small auto retailers.

On the other hand, the SMEs had also increased their own accessibility to customers and potential partners by always being accessible. For LHL, this was seen as an important benefit:

"Definitely, telecommunications is important to us in many ways such as, connecting with customers, connecting with all the importers, suppliers, and getting wider coverage" (manager of LHL).

The incoming customer calls to the mobiles were mainly limited to the use of mobile voice, and SMS messages from customers were rare. However, partners and business contacts sometimes sent SMS to get detailed information or to follow up mobile dialogues.

In our study it is hard to separate the mobilization of resources from investment or return, since that would require more detailed information about the content of the communications. These processes are after all intertwined in everyday interactions at work. What our cases suggest, however, is that many calls and messages were directed to access resources from the closer family/friend circles, rather than more distant acquaintances or business partners. The mobile communication seemed to facilitate mobilization of resources in the networks of strong ties, rather than the weaker connections. Frequent calls to friends and family can be seen as an indicator that mobile and SMS were used as a 
channel to give and receive social support. For many of the foreign workers the mobile was clearly important as a way to keep in contact with close family members in other countries, such as Cambodia and Indonesia.

The importance of trust for these small retailers was hard to overlook. The building up of trust relations, and the mobilization of them, seemed to be embedded in a long chain of regular meetings and interactions face-to-face. The small retailers seemed to be intertwined in what often is described as embedded relationships ${ }^{10}[30,32]$. The role of the mobile in this setting seemed to be for regular inbetween calls to partners and suppliers, to sort out potential problems and misunderstandings to ensure that trust would not be jeopardized. Thus it seemed that the mobile was important not only to mobilize but to sustain trusting ties.

The daily use of mobile phones seem to help the retailers to gain access to, and to mobilize, social capital resources. As such it can be seen as an artifact used to sustain and mobilize social capital resources. According to the draft model presented earlier in this paper, we should expect that the mobile phone to give the retailers particular instrumental and/or expressive returns. The emphasis from our informant was, as seen above, mainly related to instrumental gains related to savings of time, getting access to new customer bases, and improvement of information flow within the company. Given the interconnectedness of business and family relations, there are reasons to believe that the mobile phone helped to produce both these types of benefits, although the boundaries between them are blurred. A further specification of benefits - and liabilities - for small enterprises are beyond the scope of this paper, although it has touched upon in other works, focusing on mobile use in developing countries [73-75].

\section{CONCLUSIONS}

Former research has to a certain degree been able to support the argument that mobile phones alongside other types of ICT can increase the efficiency of small enterprises. On a general level, managers of small enterprises tend to report that they believe that the mobile makes their businesses more profitable $[76,77]$. This was a point of view that was shared among the managers in our cases: most managers believed that mobiles were positive for their business and made them more efficient. This 'positive impact' has, however, been further explored in this paper, by investigating how mobiles are used to support social relations by employees and managers in three small retail enterprises. We found that the mobile was used mainly to develop and strengthen existing strong ties to friends and

\footnotetext{
${ }^{10}$ The main components that embedded relationships have, are to regulate exchange partners' behaviours and expectations: facilitation of trust, fine-grained information exchange and joint problem-solving. Uzzi defines embeddedness as: "the process by which social relations shape economic action" (Uzzi 1996: 674).
}

family as well as local vendors and suppliers. In particular, it was used to coordinate and make formal agreements inbetween the regular physical meetings. Thus, the hope expressed by UNDP earlier in this paper, that ICT could “connect vast networks of SME's across geographical distances", might still be out of range when it comes to mobile use among small retailers in Malaysia. Yet, the emergent use of SMS to support and cultivate customer relations indicates how mobile applications in the future may go beyond these local networks to handle a wider set of relations through messaging systems.

This paper has drawn on a resource dependency based framework for analyzing social capital, focusing on mobile phone as a tool that may be used both to increase their access to new relational resources and mobilize pre-existing connections. The cases analyzed in this paper indicate that so far, the mobile phone was mainly a vehicle to mobilize pre-existing connections, mainly within the spheres of the close families and friends.

\section{ACKNOWLEDGMENT}

The author wishes to thank collaborators at Telenor Research and Innovation Center Asia Pacific (TRICAP) and the retailers who participated in this study.

\section{REFERENCES}

[1] G. T. T. Sin, "The Management of Chinese Small-Business Enterprises in Malaysia," Asia Pacific Journal of Management, vol. 4, pp. 178-186, 1987.

[2] C. Castelli, "SMEs in Malaysia: leading in mobility," 2007.

[3] A. S. Saleh and N. O. Ndubusi, "An Evaluation of SME Development in Malaysia," International Review of Business Research Papers, vol. 2, pp. 1-14, 2006.

[4] K. J. Kumar and A. O. Thomas, "Telecommunications and Development. The Cellular Mobile "Revolution" in China and India," Journal of Creative Communication, pp. 297-309, 2006.

[5] G. L. Harris, "United Nations Development Information Programme. ICT 4D - SME \& Entrepreneurship in Asia-Pacific," UNDP, 2003.

[6] O. K. Ting, "SMEs in Malaysia. Pivotal points for change," 2004.

[7] J. Goodman, "Linking mobile phone ownership and use to social capital in rural South Africa and Tanzania," 3, 2005.

[8] R. Ling, The Mobile Connection. The cell phone's impact on society. San Fransisco: Elsevier, Morgan Kaufmann, 2004.

[9] J. Katz and M. Aakhus, "Conclusions:making meaning of mobiles - a theory of Apparatgeist," in Perpetual Contact. Mobile communication, private talk, public performance, J. Katz and M. Aakhus, Eds., Cambridge: Cambridge University Press, 2002, pp. 301-320.

[10] K. J. Arrow, "Observations on social capital ," in Social capital: A multifaceted perspective P. Dasgupta and I. Serageldin, Eds., Washington, D.C.: The World Bank., 2000, pp. 3-5.

[11] EuropeanCommission. (2009). Enterprise and industry -SME definition.http://ec.europa.eu/enterprise/policies/sme/facts-figuresanalysis/sme-definition/index_en.htm

[12] SMIDEC, "SME performance report 2005," SMIDEC, Kuala Lumpur, Malaysia2006.

[13] P. Vandenberg, "Is Asia adopting flexicurity? A survey of employment policies in six countries," International Labour Office, Geneva 4, 2008.

[14] H. Aldrich and E. Auster, "Ewen dwarf started small: Liabilities of size and age and their strategic implications," in Research in Organizational Behavior. vol. 8, M. Staw and L. L. Cummings, Eds., Greenwich: JAI press, 1986, pp. 165-198. 
[15] R. Ellis, "Underdstanding small business networking and ICT: Exploring face-to-face and ICT-related opportunity creation mediated by social capital in East of ENgland micro-businesses," 2010 .

[16] A. Millington, et al., "Guanxi and supplier search mechanisms in China," Huma Relations, vol. 59, pp. 505-531, 2006.

[17] W.-P. Wu and A. Leung, "Does a Micro-Macro Link Exist Between Managerial Value Reciprocity, Social Capital and Firm Performance? The Case of SMEs in China," Asia Pacific Journal of Management, vol. 22, pp. 445-463, 2005.

[18] N. Tichy and C. Fombrun, "Network Analysis in Organizational Settings," Human Relations, vol. 32, pp. 923-965, 1979.

[19] M. Kilduff and W. Tsai, Social Networks and Organizations. London: Sage, 2003.

[20] P. R. Monge and N. S. Contractor, Theories of Communication Networks. New York: Oxford University Press, 2003.

[21] A. Greve and J. Salaff, "The development of corporate social capital in complex innovation processes," Research in the sociology of organizations: social capital in organizatons, vol. 18, pp. 107-134, 2001 .

[22] D. Knoke, "Organizational Networks and Corporate Social Capital," in Corporate Social Capital and Liability, R. T. Leenders and S. M. Gabay, Eds., Dordrecht: Kluwer Academic Publ, 1999, pp. 17-42.

[23] W. Powell, "Trust-based Forms of Governance," in Trust in Organizations.Frontiers of Theory and research, R. Kramer and T. Tyler, Eds., Thousand oaks: Sage, 1996, pp. 51-67.

[24] J. Nahapiet and S. Ghoshal, "Social Capital, intelectual capital and the organizational advantage," Academy of Management Journal, vol. 23, 1998.

[25] J. Field, Social Capital. London, 2003.

[26] A. Portes, "Social Capital. Its Origins and Applications in Modern Sociology," Annual Reviews in Sociology, pp. 1-24, 1998.

[27] D. Knoke, Changing Organizations. Business Networks in the New political Economy: Westview Press, 2001.

[28] N. Lin, Social Capital. A Theory of Social Structure and Action. New york: Cambridge University Press, 2001.

[29] N. Lin, "Building a Network Theory of Social Capital," Connections, vol. 22, pp. 28-51, 1999

[30] M. S. Granovetter, "Economic, action, social structure, and embeddedness," American Journal of Sociology, pp. 481-510, 1985.

[31] D. M. Rousseau, et al., "Not So Different After All: A CrossDisipline View of Trust," Academy of Management Journal, vol. 3, pp. 393-404, 1998.

[32] B. Uzzi, "Social structure and competition in interfirm networks: The paradox of embeddedness.," Administrative Science Quarterly, pp. 35-67, 1997.

[33] A. Giddens, "Risk, trust, reflexivity," in Reflexive Modernization, U. Beck, et al., Eds., Cambridge UK: Polity Press, 1994, pp. 184-197.

[34] R. Bachmann and A. Zaheer, Eds., Handbook of Trust Research. Cheltenham, UK: Edward Elgar, 2006.

[35] R. M. Kramer and K. S. Cook, "Trust and Distrust in organizations: Dilemmas and Approaches," in Trust and Distrust in organizations. Dilemmas and Approaches, R. M. Kramer and K. S. Cook, Eds., New York: Russel Sage Foundation, 2004, pp. 1-17.

[36] S. M. Gabbay and R. T. A. J. Leenders, "Social Capital of Organizations: From Social Structure to the Management of Corporate Social Capital," in Social capital of Organizations. vol. 18, S. M. Gabbay and R. T. A. J. Leenders, Eds., Oxford, UK: Elsevier Science, 2001, pp. 1-20.

[37] F. Fukuyama, "Trust. The Social Virtues and the Creation of Prosperity," New York, vol. , p. , 1995.

[38] R. Putnam, Bowling Alone: The Collapse and Revival of American Community. New York: Simon Schuster, 2000

[39] P. S. Adler, "Market, hierarchy, and trust: The knowledge economy and the future of capitalism," Organization Science, vol. 12, pp. 215 234, 2001.

[40] P. S. Adler and C. Heckscher, "Towards Collaborative Community," in The Firm as a Collaborative Community, C. Heckscher and P. Adler, Eds., New York: Oxford University Press, 2006, pp. 11-105.
[41] P. S. Adler and S.-W. Kwon, "Social capital: Prospects for a New Concept," Academy of Management Journal, vol. 27, pp. 17-40, 2002.

[42] E. Shaw, "Small Firm Networking," International Small Business Journal, vol. 24, pp. 5-29, 2006.

[43] B. Johannison, "Network Strategies: Management Technology for Entrepreneurship and Change.," International Small Business Journal, vol. 5, pp. 49-63, 1986.

[44] D. Krackhardt and M. Kilduff, "Structure, Culture and Simmelian ties in entrepreneurial firms," Social Networks, vol. 3, pp. 279-290, 2002.

[45] M. S. Granovetter, "The Strength of Weak Ties," American Journal of Sociology, pp. 1287-1303, 1973.

[46] M. T. Hansen, et al., "So Many Ties, So Little Time: A Task Contingency Perspective on Corporate Social Capital," Research in the Sociology of Organizations, pp. 21-57, 2001.

[47] D. Krackhardt and R. N. Stern, "Informal Networks and Organizational Crises: An Experimental Simulation," Social Psychology Quarterly, vol. 51, pp. 123-140, 1988.

[48] J. Coleman, "Social capital in the creation of human capital," American Journal of Sociology, pp. 95-120, 1988.

[49] B. Nardi, et al., "It's Not What You Know, It's Who You Know: Work in the Information Age," First Monday, vol. 5, p. http://firstmonday.org/issues/issue5_5/nardi/index.html 2000.

[50] D. Krackhardt, "The strength of strong ties: The importance of philos in organizations," in Network and Organizations; Structure, Form and Action, N. Nohria and R. Eccles, Eds., Boston: Harvard University Press, 1992, pp. 216-239.

[51] R. Burt, Brokerage and Closure. An Introduction to Social Capital. New York: Oxford University Press, 2005.

[52] J. Podolny and J. Baron, "Resources and relationships, social networks and mobility in the workplace," American Sociological Review, pp. 673-693, 1997.

[53] C. Licoppe and Z. Smoreda, "Are social networks technologically embedded? How networks are changing today with changes in communication technology," Social Networks, pp. 317-335, 2004.

[54] E. M. Rogers and D. L. Kincaid, Communication Networks. Toward a new paradigm for research. New york: The Free Press, 1981.

[55] R. McPhee and S. R. Corman, "An activity-based theory of communication networks in organizations, applied to the case of a local church," Communication Monographs, vol. 62, pp. 132-151, 1995.

[56] C. Tilly, Trust and Rule. Cambridge: Cambridge University Press, 2005.

[57] L. Joseph, "Inter-city Marketing Network for Women Microentrepreneurs using Cell Phone," in I4D Information for development vol. http://www.i4donline.net/feb05/intercity.asp, 2005.

[58] R. Ling and T. E. Julsrud, "Grounded Genres in Multimedia Messaging," in The Global and the Local in Mobil Communication, K. Nyiri, Ed., Vienna: Passagen Verlag, 2005, pp. 329-338.

[59] T. E. Julsrud and J. W. Bakke, "Trust, friendship and expertise: The use of email, mobile dialogues and SMS to develop and sustain social relations in a distributed work group," in The mobile communications research annual: The reconstruction of space and time through mobile communication practices vol. 1, R. Ling and S. Campbell, Eds., New Brunswick, NJ Transaction, 2008.

[60] C. Haythornthwaite, "Strong, Weak, and Latent Ties and the Impact of New Media " The Information Society, vol. 18, pp. 385-401, 2002.

[61] R. Yin, Case Study Research. Design and Methods, Third ed. vol. 5. Thousand Oaks: Sage, 2003.

[62] M. B. Miles and A. M. Huberman, Qualitative Data Analysis: an expanded sourcebook. Thousand Oaks: Sage, 1994.

[63] J.-A. Carrasco, et al., "Collecting Social Network Data to Study Social Activity-Travel Behaviour: An Egocentric Approach " in The 85th Transportation Research Board Meeting,January 22-26, 2006., Washington DC, 2006.

[64] B. Wellman, "Challenges in Collecting Personal Network Data: The Nature of Personal Network Analysis," Field Methods, vol. 19, pp 111-115, 2007. 
[65] R. H. Bernhardt, et al., "Informant accuracy in social network data V.," Social Science Research, pp. 30-66, 1982.

[66] T. E. Julsrud, "Collaboration Patterns in Distributed Work Groups: A Cognitive Network Approach" Telektronikk, pp. 60-71, 2008.

[67] J. Donner, "The Use of Mobile Phones by Microentrepreneurs in Kigali and Rwanda: Changes to Social and Business Networks," Information Technology and International Development, vol. 3, pp. 3-19, 2006.

[68] J. Donner, "Microenterpreneurs and mobiles: an exploration of the uses of mobile phones by small business owners in Rwanda," Information Technology and International Development, vol. 2, pp. 1-21, 2004

[69] J. R. Tyler, et al., "Email as spectroscopy: automated discovery of community structure within organizations," The Information Society, vol. 21, pp. 143-153, 20052005.

[70] J. Larsen, et al., Mobilities, Networks, Geographies. Hampshire: Ashgate, 2006.

[71] R. Ling and B. Yttri, "Hyper-coordination via mobile phones in Norway," in Perpetual Contact: Mobile Communication, Private Talk, Public Performance, J. Katz and M. Aakhus, Eds., Cambridge: Cambridge University Press, 2004, pp. 139-169.

[72] R. Rettie, "Mobile phones as social capital," Mobilities, vol. 3, pp. 291-311, 2010.

[73] R. Jensen, "The digital provide: Information (technology) market performance and welfare in the South Indian fisheries sector," Quarterly Journal of Economics, vol. 122, pp. 879-924, 2007.

[74] J. Donner and M. Escobari, "A reviev of the research on mobile use by micro and small enterprises (MSEs)," in 3rd Annual conference on Information Communication Technologies and Development. April 17th-19th, 2009 Quatar Eduction City, Doha, Quatar., 2009.

[75] A. Jagun, et al., "The Impatc of Mobile Telephony on Developing Country Micro-Enterprise: A Nigerian Case Study," Information Technologies and International Development, vol. 4, pp. 47-65, 2008.

[76] J. Samuel, et al., "Mobile Communication in South Africa, Tanzania and Egypt: Results from Community and Business Surveys," http://www.vodafone.com/start/media relations/news/group_press $r$ eleases/2005/press_release09_03.html, 2005.

[77] R. Duncombe and R. Heeks, "Enterprise Across the Digital Divide: Information Systems and Rural Microenterprise in Botswane," Journal of Internalonal Development, vol. 14, pp. 61-74, 2002. 